Article

\title{
Flavonoids-Rich Orthosiphon stamineus Extract as New Candidate for Angiotensin I-Converting Enzyme Inhibition: A Molecular Docking Study
}

\author{
Armaghan Shafaei ${ }^{1}$, Md Shamsuddin Sultan Khan ${ }^{2}$, Abdalrahim F. A. Aisha ${ }^{1}$, \\ Amin Malik Shah Abdul Majid ${ }^{2}$, Mohammad Razak Hamdan ${ }^{3}$, Mohd Nizam Mordi ${ }^{3}$ \\ and Zhari Ismail ${ }^{1, *}$ \\ 1 Department of Pharmaceutical Chemistry, School of Pharmaceutical Sciences, Universiti Sains Malaysia, \\ Minden, Penang 11800, Malaysia; armaghn.shafaei@gmail.com (A.S.); abedaisheh@yahoo.com (A.F.A.A.) \\ 2 EMAN Testing \& Research Laboratory, Department of Pharmacology, School of Pharmaceutical Sciences, \\ Universiti Sains Malaysia, Minden, Penang 11800, Malaysia; jupitex@gmail.com (M.S.S.K.); \\ aminmalikshah@usm.my (A.M.S.A.M.) \\ 3 Centre for Drug Research, Universiti Sains Malaysia, Minden, Penang 11800, Malaysia; \\ ikraqlah@gmail.com (M.R.H.); mnizam@usm.my (M.N.M.) \\ * Correspondence: ismailzhari@gmail.com; Tel.: +60-4-653-4222; Fax: +60-4-657-0017
}

Academic Editors: Celestino Santos-Buelga and Arturo San Feliciano

Received: 22 August 2016; Accepted: 28 October 2016; Published: 9 November 2016

\begin{abstract}
This study aims to evaluate the in vitro angiotensin-converting enzyme (ACE) inhibition activity of different extracts of Orthosiphon stamineus (OS) leaves and their main flavonoids, namely rosmarinic acid (RA), sinensetin (SIN), eupatorin (EUP) and 3'-hydroxy-5,6,7, $4^{\prime}$-tetramethoxyflavone (TMF). Furthermore, to identify possible mechanisms of action based on structure-activity relationships and molecular docking. The in vitro ACE inhibition activity relied on determining hippuric acid (HA) formation from ACE-specific substrate (hippuryl-histidyl-leucine (HHL)) by the action of ACE enzyme. A High Performance Liquid Chromatography method combined with UV detection was developed and validated for measurement the concentration of produced HA. The chelation ability of OS extract and its reference compounds was evaluated by tetramethylmurexide reagent. Furthermore, molecular docking study was performed by LeadIT-FlexX: BioSolveIT's LeadIT program. OS ethanolic extract (OS-E) exhibited highest inhibition and lowest $\mathrm{IC}_{50}$ value $(45.77 \pm 1.17 \mu \mathrm{g} / \mathrm{mL})$ against ACE compared to the other extracts. Among the tested reference compounds, EUP with $\mathrm{IC}_{50} 15.35 \pm 4.49 \mu \mathrm{g} / \mathrm{mL}$ had highest inhibition against $\mathrm{ACE}$ and binding ability with Zn (II) $(56.03 \% \pm 1.26 \%)$ compared to RA, TMF and SIN. Molecular docking studies also confirmed that flavonoids inhibit ACE via interaction with the zinc ion and this interaction is stabilized by other interactions with amino acids in the active site. In this study, we have demonstrated that changes in flavonoids active core affect their capacity to inhibit ACE. Moreover, we showed that ACE inhibition activity of flavonoids compounds is directly related to their ability to bind with zinc ion in the active site of ACE enzyme. It was also revealed that OS extract contained high amount of flavonoids other than RA, TMF, SIN and EUP. As such, application of OS extract is useful as inhibitors of ACE.
\end{abstract}

Keywords: angiotensin-converting enzyme; hypertension; flavonoids; HPLC-UV; molecular ducking study

\section{Introduction}

Hypertension or high blood pressure is one of the main causes of death in industrialized societies [1]. Globally, about one-quarter of the adult population suffers from hypertension [2]. It is 
a major risk factor for cardiovascular disease and related complications, such as heart disease, kidney damage, eye damage and stroke [3]. Lifestyle modifications, including changes in dietary habits, might avoid, delay or reduce the need for medication [4].

The renin-angiotensin-aldosterone system (RAAS) is a key factor in the maintenance of arterial blood pressure. Angiotensin-converting enzyme (ACE) (EC3.4.15.1) is one of the main components of the RAAS [5]. ACE is a glycosylated zinc dipeptidyl-carboxypeptidase, and its main function is catalyzing the conversion of the precursor angiotensin I into angiotensin II. ACE is a peptide responsible for triggering vasoconstrictive effects to regulate arterial blood pressure and electrolyte balance and degrades bradykinin, which is a potent vasodilator in RAAS. Therefore, inhibition of ACE has become a promising way for regulation and treatment of high blood pressure [6].

Although nowadays many synthetic ACE inhibitors such as captopril, benazepril, enlapril and alacepril are widely used in the treatment of hypertension and heart failure, the chronic use of these synthetic inhibitors may be associated with many undesirable side effects, such as persistent cough, postural hypotension, renal failure, and angioedema [7-9]. Recently, many studies have been carried out to discover new ACE inhibitor compounds from natural resources [10,11]. Natural ACE inhibitors as alternatives to synthetic ones have great interest among researchers for their better drug profiles and fewer side effects [12]. The ACE inhibition of natural substances, such as peptides and triterpenes, has been described in the literature [13-15]. Recent studies also demonstrated beneficial in vitro ACE inhibition effect of flavonoids compounds isolated from different plants [16-18]. These beneficial effects have largely been ascribed to the generation of chelate complexes within the active center of ACE [19]. Phenolic compounds such as ferulic acid and tannic acid and flavonoids such as quercetin, anthocyanins, flavones and flavonols have shown to exhibit a capacity to inhibit different zinc metalloproteinases, including ACE [19-25]. Moreover, the ACE-inhibitory (ACE-I) activity of different foods and plant extracts rich in flavonoids have also been demonstrated by in vitro and in vivo studies in spontaneous hypertensive rats $[16,26-28]$. However, only a few studies have been done to address the relationship between the ACE-I activity of flavonoids compounds and their structures [12,14].

There are several methods that have been proposed for the measurement of ACE activity such as spectrophotometry, High-performance liquid chromatography (HPLC), fluorimetry and micellar electrokinetic chromatography [29-31]. Among the methods, spectrophotometry and HPLC methods are employed most frequently [29]. The spectrophotometric method developed by Cushman and Cheung (1971) is the most commonly utilized in vitro assay [32]. This method uses the ACE-specific substrate hippuryl-histidyl-leucine (HHL) coupled with spectrophotometric detection of the product hippuric acid (HA). This method relies on the principle of determining hippuric acid formation from HHL by the action of ACE, resulting in the removal of C-terminal dipeptide histidylleucine. However, ethyl acetate extraction procedure in spectrophotometry method can also extract unhydrolyzed HHL apart from HA, therefore incorrect positive results cannot be excluded [33]. Alternatively, HPLC, as an analytical technique, has provided specific quantification of compounds at low concentrations. Moreover, the accuracy and reproducibility than spectrophotometry makes it well suited for quantitative study of enzymatic-catalyzed reaction that those not require a chromophore or radiolabeling [34].

Orthosiphon stamineus Benth. (OS) or misai kucing is a plant from Lamiaceae family. It is a medicinal plant and native in Southeast Asia. The leaves of this plant have been reported to have anti-diabetes, anti-hypertension, diuretic and anti-cancer effects [35-38]. OS leaves have been reported to contain high content of phenolic acid such as rosmarinic acid (RA) and flavonoids contents, such as sinensetin (SIN), eupatorin (EUP) and 3'-hydroxy-5,6,7,4'-tetramethoxyflavone (TMF) [39]. Therefore, this plant is an important candidate to develop a drug with ACE inhibition activity. Therefore, the objectives of this study are to evaluate the in vitro ACE inhibition activity of different extracts of OS leaves, three flavonoids sinensetin (SIN), eupatorin (EUP) and 3'-hydroxy-5,6,7,4'-tetramethoxyflavone (TMF) belonging to lipophilic flavones and a caffeic acid derivative, phenolic rosmarinic acid (RA), by developing a new HPLC-UV method. Moreover, this study investigates the chelation ability of 
Zinc (II) Ion by the main flavonoids and phenolic compounds presence in OS extracts. The results will be used to identify possible mechanisms of action based on structure-activity relationships and molecular docking.

\section{Results}

\subsection{Identification and Quantification of RA,TMF, SIN and EUP in OS Extracts}

The HPLC/MS was applied for identifcation of RA, TMF, SIN and EUP in different extracts of OS. The standard compounds of RA, TMF, SIN and EUP were analyzed in both negative and positive ESI mode. The results showed that ESI in positive mode was sensitive to all tested compounds. All four standard compounds were well detected. The detected constituents all exhibited their quasi-molecular ions $[\mathrm{M}-\mathrm{H}]^{+}$(Figure 1$)$.
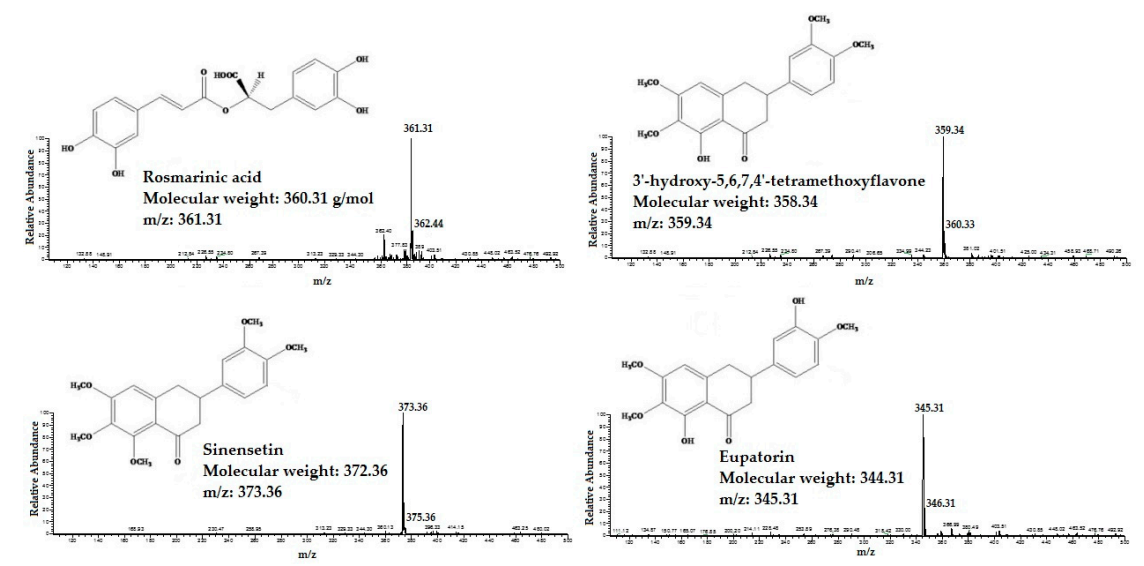

Figure 1. The High performance liquid chromatography-mass spectrometry (HPLC/MS) spectra of standard compounds: $3^{\prime}$-hydroxy-5,6,7, $4^{\prime}$-tetramethoxyflavone, eupatorin, sinensetin and rosmarinic acid.

By carefully studying the mass spectra of standard compounds and comparing them with the mass spectra of different extracts of OS, the peak related to the standard compounds in the extracts were designated and identified (Figure 2). They were: (1) RA; (2) TMF; (3) SIN; and (4) EUP. As shown in Figure 2, TMF (2) was not detected in OS-W and OS-MW samples.
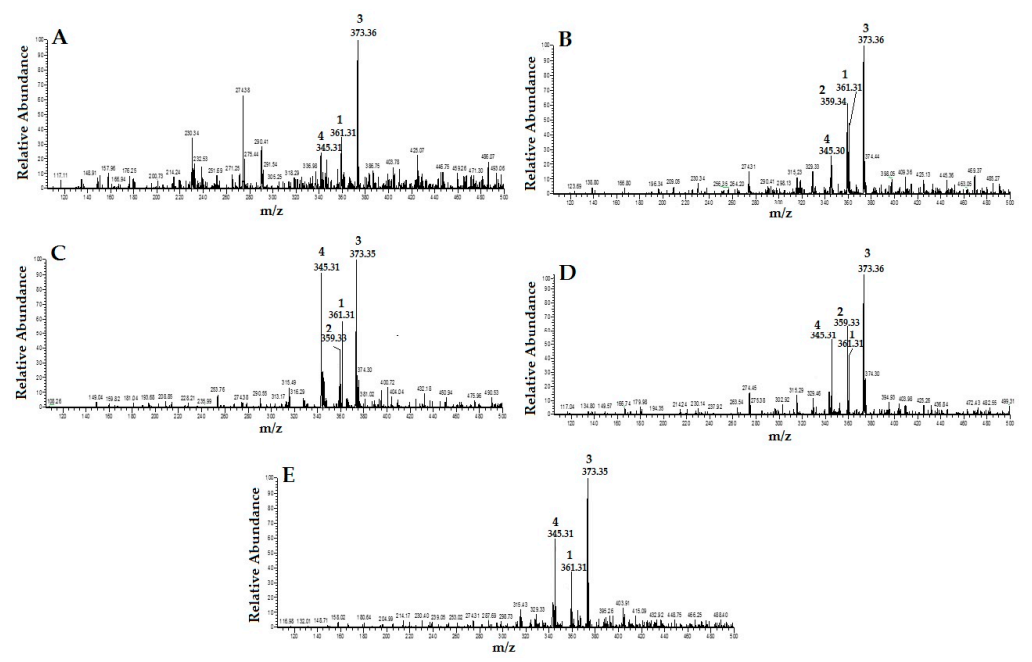

Figure 2. HPLC/MS spectra of different extracts of Orthosiphon stamineus (OS) (1: RA; 2: TMF; 3: SIN; and 4: EUP): (A) water extract (OS-W); (B) ethanolic extract of (OS-E); (C) methanolic extract of (OS-M); (D) $50 \%$ ethanolic extract (OS-EW); and (E) 50\% methanolic extract (OS-MW). 
The HPLC method was applied for quantification of RA, TMF, SIN and EUP in OS extracts. As shown in Figure 3, selected standard compounds were well separated by the described HPLC method. In Table 1, concentrations of RA, TMF, SIN and EUP determined by HPLC in different extracts of OS are presented. Results were derived from the mean of peak area from three replicates injections. The results show that concentration of RA in OS-EW (235.5 $\pm 0.2 \mathrm{mg} / \mathrm{g})$ and concentrations of TMF, SIN and EUP $(11.5 \pm 1.0,23.2 \pm 0.1$ and $166.9 \pm 3.5 \mathrm{mg} / \mathrm{g})$ in OS-E were higher compared to other extracts. Results from this study are in line with previous reports suggesting that lipophilic flavones (TMF, SIN and EUP) are the major bioactive constituents in OS-E [40].

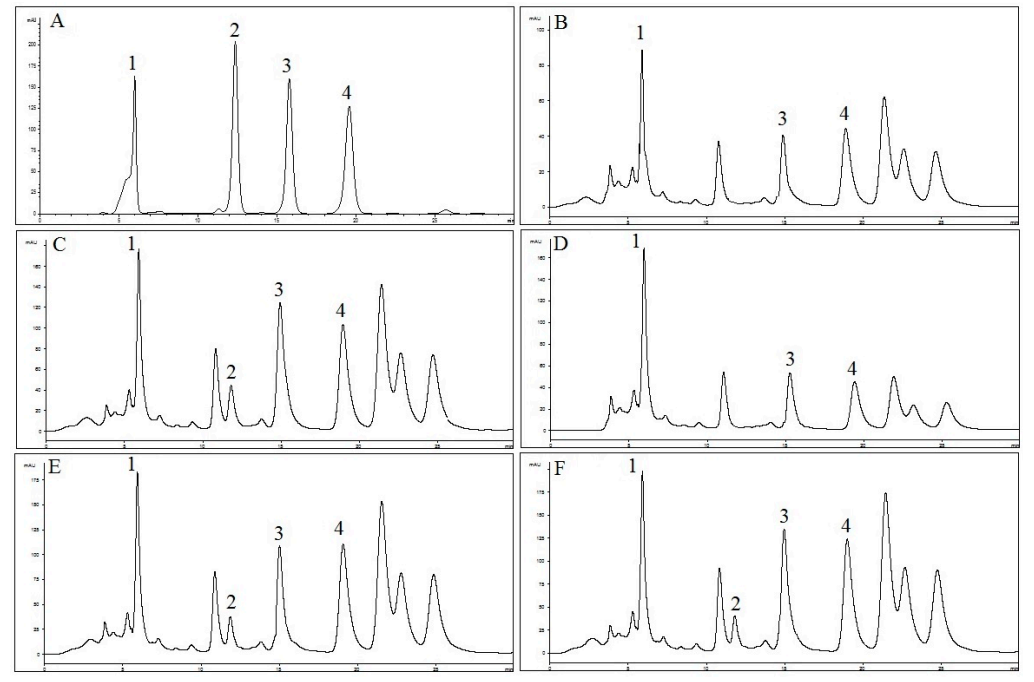

Figure 3. HPLC chromatograms of: (A) reference compounds (1: RA; 2: TMF; 3: SIN; and 4: EUP); (B) OS-W; (C) OS-E; (D) OS-M; (E) OS-EW; and (F) OS-MW at $330 \mathrm{~nm}$.

Table 1. Quantification of four marker compounds in OS extracts. Results are shown as average (mg/g; marker compound/extract).

\begin{tabular}{cccccc}
\hline Component & $\begin{array}{c}\text { Water Extract } \\
\text { (OS-W) }\end{array}$ & $\begin{array}{c}\text { Ethanolic Extract } \\
\text { (OS-E) }\end{array}$ & $\begin{array}{c}\text { Methanolic Extract } \\
\text { (OS-M) }\end{array}$ & $\begin{array}{c}\mathbf{5 0 \%} \text { Ethanolic Extract } \\
\text { (OS-EW) }\end{array}$ & $\begin{array}{c}\mathbf{5 0 \%} \text { Methanolic Extract } \\
\text { (OS-MW) }\end{array}$ \\
\hline RA & $31.0 \pm 0.2$ & $219.8 \pm 0.6$ & $200.8 \pm 1.5$ & $235.5 \pm 0.2$ & $212.3 \pm 0.01$ \\
TMF & $0.0 \pm 0.7$ & $11.5 \pm 1.0$ & $0.0 \pm 0.2$ & $4.3 \pm 0.01$ & $0.9 \pm 0.01$ \\
SIN & $3.2 \pm 0.01$ & $23.2 \pm 0.1$ & $6.1 \pm 0.01$ & $10.5 \pm 0.01$ & $8.0 \pm 0.3$ \\
EUP & $2.3 \pm 0.01$ & $166.9 \pm 3.5$ & $22.4 \pm 0.3$ & $66.8 \pm 0.9$ & $30.6 \pm 0.1$ \\
\hline
\end{tabular}

\subsection{Validation of HPLC Method for Measurement of ACE Inhibition Activity}

In this work, the analyses were carried out by HPLC-UV, and HHL was used as substrate. The choice of the substrate was based on the sensitivity (corresponding detection limits have been estimated), the cost and more importantly the ACE amounts required for hydrolysis [29]. Under the aforementioned HPLC conditions, complete base line separation of HA and HHL was achieved on a Zorbax Eclipse plus phenyl-hexyl column. HA and HHL were eluted at 4.9 min and $8.3 \mathrm{~min}$, respectively. The total time for the separation of HHL and HA was $10 \mathrm{~min}$. For ACE reaction mixture, elution profile of HA and HHL was similar to the observed ones for their corresponding standards. Linearity of the method was evaluated by determining a series of seven working standards solution of HA in three replicates.

Different concentrations of ACE enzyme (0.05-0.00157 U/mL) were reacted with HHL to measure produced HA. A linear regression equation and correlation coefficient were established from the graph by plotting the mean of three replicates peak areas of HA versus the HA concentration and three replicates peak areas of HA versus ACE concentration. It was found that the HA solution was linear over the evaluated concentration range with $R^{2}>0.999$. The sensitivity of the method was evaluated 
by Limit of Detection (LOD) and Limit of Quantification (LOQ) analyses. The values of LOD and LOQ for HA were $0.14 \pm 0.00$ and $0.44 \pm 0.00 \mu \mathrm{g} / \mathrm{mL}$, respectively. The peak areas were used to calculate relative standard deviation (\%RSD) of the reference compounds, and intra-day and inter-day precision rates. The variations were found to be in the range of $97.71 \%-102.28 \%$ for HA with RSD less than $2 \%$. For recovery rates, they ranged between $99.00 \%$ and $101.7 \%$, with RSD less than 3\%, which indicates that the applied method is reproducible.

\subsection{In Vitro ACE Inhibition Activity}

Different extracts of OS and compounds of RA, TMF, SIN and EUP were evaluated for the substantive experiment of the rapid in vitro assay of ACE inhibition. The results of ACE inhibitory activity of OS extracts and reference compounds at the concentration range of $(3.125-50 \mu \mathrm{g} / \mathrm{mL}) \mathrm{are}$ shown in Figure 4. Captopril, a synthetic ACE-I, was used as a positive control. The half maximal inhibitory concentration $\left(\mathrm{IC}_{50}\right.$ ) value is deduced from the linear regression equation obtained by plotting percentage ACE inhibition activity versus concentration. Table 2 depicts $\mathrm{IC}_{50}$ values of the extracts and positive control. The OS-E exhibits highest inhibition and lowest $\mathrm{IC}_{50}$ value $(45.77 \pm 1.17 \mu \mathrm{g} / \mathrm{mL})$ against ACE compared to the other extracts. The ACE inhibitory activity of all extracts follows the order: OS-E > OS-M > OS-EW > OS-MW > OS-W. Among the reference compounds, EUP showed the highest inhibition lowest $\mathrm{IC}_{50}(15.35 \pm 4.49 \mu \mathrm{g} / \mathrm{mL})$ value.

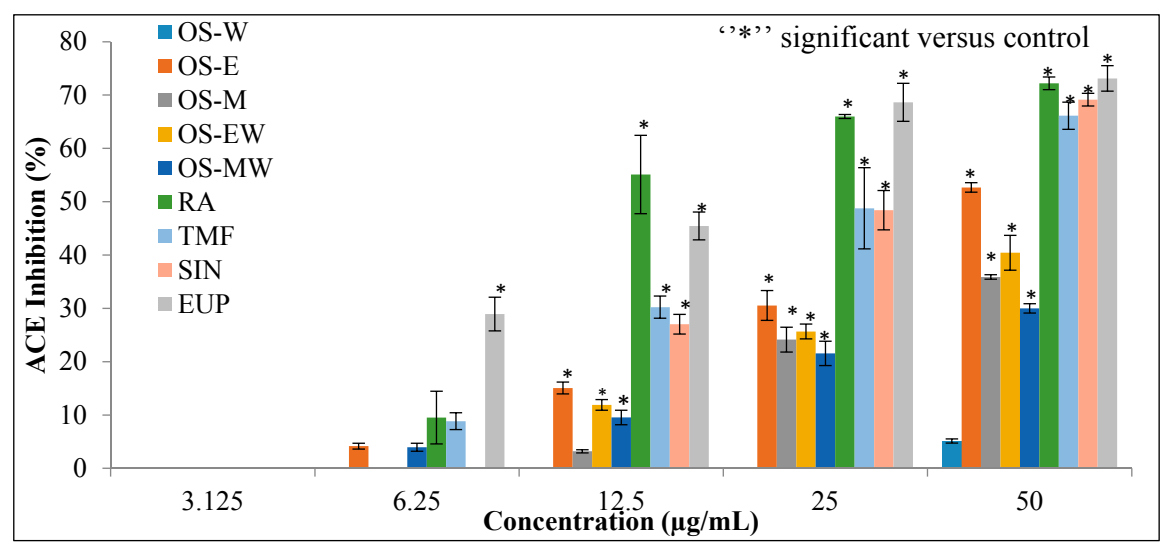

Figure 4. The dose-response relationship of OS extracts and reference compounds on in vitro ACE inhibitory assay. Data are presented as mean $\pm \mathrm{SD},(p<0.05)$.

Table 2. The half-maximal inhibitory concentration $\left(\mathrm{IC}_{50}\right)$ of OS extracts, standard compounds and captopril on in vitro ACE inhibitory assay, each value represents mean $\pm \operatorname{SD}(n=3)$.

\begin{tabular}{ccc}
\hline Components & IC $_{\mathbf{5 0}}$ & Unit \\
\hline OS-W & $358.8 \pm 24.2$ & $\mu \mathrm{g} / \mathrm{mL}$ \\
OS-E & $45.8 \pm 1.2$ & $\mu \mathrm{g} / \mathrm{mL}$ \\
OS-M & $63.7 \pm 1.1$ & $\mu \mathrm{g} / \mathrm{mL}$ \\
OS-EW & $58.1 \pm 2.0$ & $\mu \mathrm{g} / \mathrm{mL}$ \\
OS-MW & $78.2 \pm 7.9$ & $\mu \mathrm{g} / \mathrm{mL}$ \\
Captopril & $0.002 \pm 0.001$ & $\mu \mathrm{M}$ \\
RA & $18.8 \pm 0.2$ & $\mu \mathrm{g} / \mathrm{mL}$ \\
TMF & $27.9 \pm 2.4$ & $\mu \mathrm{g} / \mathrm{mL}$ \\
SIN & $29.5 \pm 0.3$ & $\mu \mathrm{g} / \mathrm{mL}$ \\
EUP & $15.4 \pm 4.5$ & $\mu \mathrm{g} / \mathrm{mL}$ \\
\hline
\end{tabular}

\subsection{Chelation of Zinc (II) Ion by OS-E, RA, TMF, SIN, EUP and Captopril}

Among the tested extracts, OS-E showed highest ACE inhibition activity. Therefore, this extract was selected to study its chelation ability with zinc (II) ion. Zn (II) chelating activity of OS-E, RA, TMF, SIN, EUP and captopril was determined by tetramethylmurexide (TMM) reagent. In the first step, 
a standard curve was constructed from the absorption of TMM and complexes of metal ions versus the concentration range of metal ions $(0-3.2 \mathrm{mmol} / \mathrm{mL})$ at $462 \mathrm{~nm}$. Based on this standard curve, the amount of metal ions bound by the compound tested was evaluated. The results demonstrated that captopril was the best chelator with $\mathrm{Zn}$ (II) $(100 \% \pm 1.59 \%$ at concentration of $4 \mathrm{mg} / \mathrm{mL})$ (Figure 5). OS-E extract also showed a high ability (79.42 \pm 1.91$)$ to bind with Zn (II) at final concentration of $5 \mathrm{mg} / \mathrm{mL}$. Among the standard compounds, EUP demonstrated the highest bounding ability with $\mathrm{Zn}$ (II) $(56.03 \% \pm 1.26 \%$ at concentration of $5 \mathrm{mg} / \mathrm{mL})$ compared to RA, TMF and SIN. SIN showed the lowest bounding ability with $\mathrm{Zn}$ (II) $(6.71 \% \pm 0.62 \%$ at concentration of $5 \mathrm{mg} / \mathrm{mL})$ in comparison to the other tested compounds.

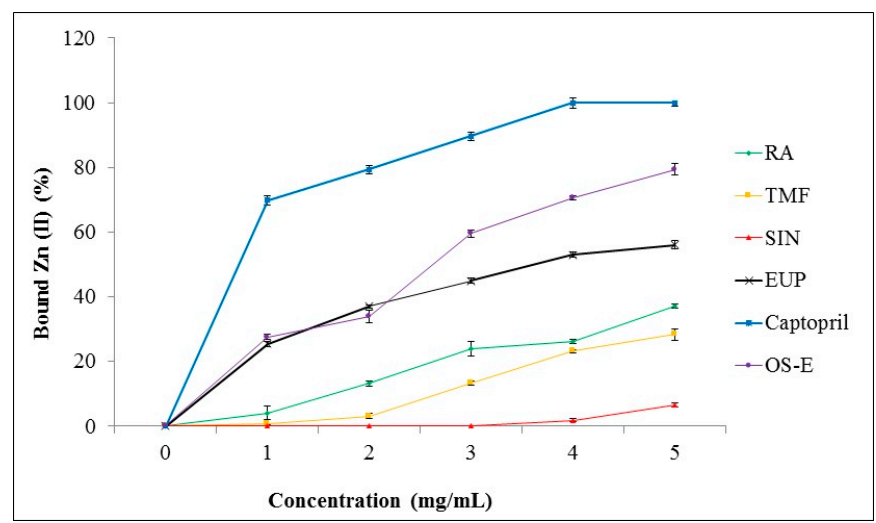

Figure 5. Zn (II) chelating activity of OS-E, RA, TMF, SIN, EUP and captopril. Data are presented as mean \pm SD.

\subsection{Molecular Docking Study}

The docking scores and binding affinities of RA, SIN, TMF, EUP and captopril compounds with the active site of ACE, which is Zn (II), were evaluated (Table 3). Captopril, as a well-known ACE inhibitor, showed the highest binding affinity energy $(\Delta \mathrm{G})$ and ligand efficiency with $-38 \mathrm{~kJ} / \mathrm{mol}$ and $0.64 \mathrm{kcal} / \mathrm{mol}$ per heavy atom, respectively. Among tested compounds, EUP had the highest binding affinity energy $(\Delta G)$ and ligand efficiency with $-29 \mathrm{~kJ} / \mathrm{mol}$ and $0.28 \mathrm{kcal} / \mathrm{mol}$ per heavy atom, respectively. After EUP, RA showed to have high possibility to bind with an active site of ACE with $-17 \mathrm{~kJ} / \mathrm{mol}$ binding affinity energy and $0.16 \mathrm{kcal} / \mathrm{mol}$ per heavy atom ligand efficiency, whereas TMF, with $-6 \mathrm{~kJ} / \mathrm{mol}$ and $0.06 \mathrm{kcal} / \mathrm{mol}$ per heavy atom, respectively, showed low binding affinity energy and ligand efficiency. In addition, SIN did not show any interaction with zinc ion in the active center of ACE.

Docking studies of flavonoids indicated that these compounds are able to inhibit ACE via interaction with zinc ion and this interaction is stabilized by other interactions with amino acids in the active site [6]. As shown in Figure 6, captopril is able to interact with zinc ion directly by its sulfhydryl group which forms a coordinate covalent bond with the metal ion. Moreover, strong hydrogen bonds between His513, His353 and the central carbonyl group adhered to ACE molecule on one site, while one of the carboxyl groups on the terminal proline interacts with the residues Tyr 520, Gln 281, and Lys 511 at the other site of ACE molecule. Furthermore, EUP and RA are able to interact with zinc ion in the active site of ACE via their ketone group (in the C4 at the C-ring) and carboxyl group, respectively. Moreover, EUP interacted with amino acid residues such as Tyr523, Hoh2570, His513, His353, Gln281 and Lys511 with its 3 hydroxy in B-ring, 5 hydroxy in A-ring, oxygen atom and ketone group at the C-ring via seven hydrogen bonds. While RA showed six hydrogen bonds via its acrylic acid and carboxyl groups with amino acid residues (Tyr523, Glu384, His353, Asn70 and Hoh2570). Concerning TMF and SIN, neither of these compounds interacted with zinc in the active site. However, these compounds formed interactions with amino acids in the active site of ACE but their binding affinity energy and ligand efficiency were very low (Table 3). 
Table 3. Summary of the docking scores and reported binding affinities of RA, SIN, TMF and EUP compounds with ACE in the docking analysis with LeadIT FlexX Scoring functions.

\begin{tabular}{llll}
\hline $\begin{array}{l}\text { Receptor-Ligand } \\
\text { Complex (LEADIT) }\end{array}$ & $\begin{array}{l}\text { Binding Affinity Energy, } \\
\Delta \mathbf{G}(\mathbf{k J} / \mathbf{m o l})\end{array}$ & $\begin{array}{l}\text { Ligand Efficiency } \\
\mathbf{( k c a l / m o l ~ P e r ~ H e a v y ~ A t o m ) ~}\end{array}$ & \multicolumn{1}{c}{$\begin{array}{l}\text { Hydrogen } \\
\text { Bonds }\end{array}$} \\
\hline ACE-RA & -17 & 0.16 & $\begin{array}{l}\text { Zn701, Tyr523, Glu384, His353, Ser355, Val516, Phe512, Asn70, } \\
\text { His353, Hoh2570, His383 and Val380 }\end{array}$ \\
\hline ACE-SIN & 10 & 0 & $\begin{array}{l}\text { Zn701, Ser355, Phe512, His383, Gln281, Lys511, Tyr523, His353, } \\
\text { His513 and Val518 }\end{array}$ \\
\hline ACE-TMF & -6 & 0.06 & $\begin{array}{l}\text { Zn701, His383, Tyr523, Hoh2409, Gln281, Gly2000, Lys511, His353, } \\
\text { Ser355, Phe512, His513 and Hoh2570. }\end{array}$ \\
\hline ACE-EUP & -29 & 0.28 & $\begin{array}{l}\text { Zn701, Hoh2570, Ser355, His353, Val518, Phe512, His513, Gln281, } \\
\text { Lys511, His513 and Tyr523 }\end{array}$ \\
\hline ACE-Captopril & -38 & 0.64 & Zn701, Tyr523, Tyr520, His513, Lys511, Gln281, His353 and His383 \\
\hline
\end{tabular}



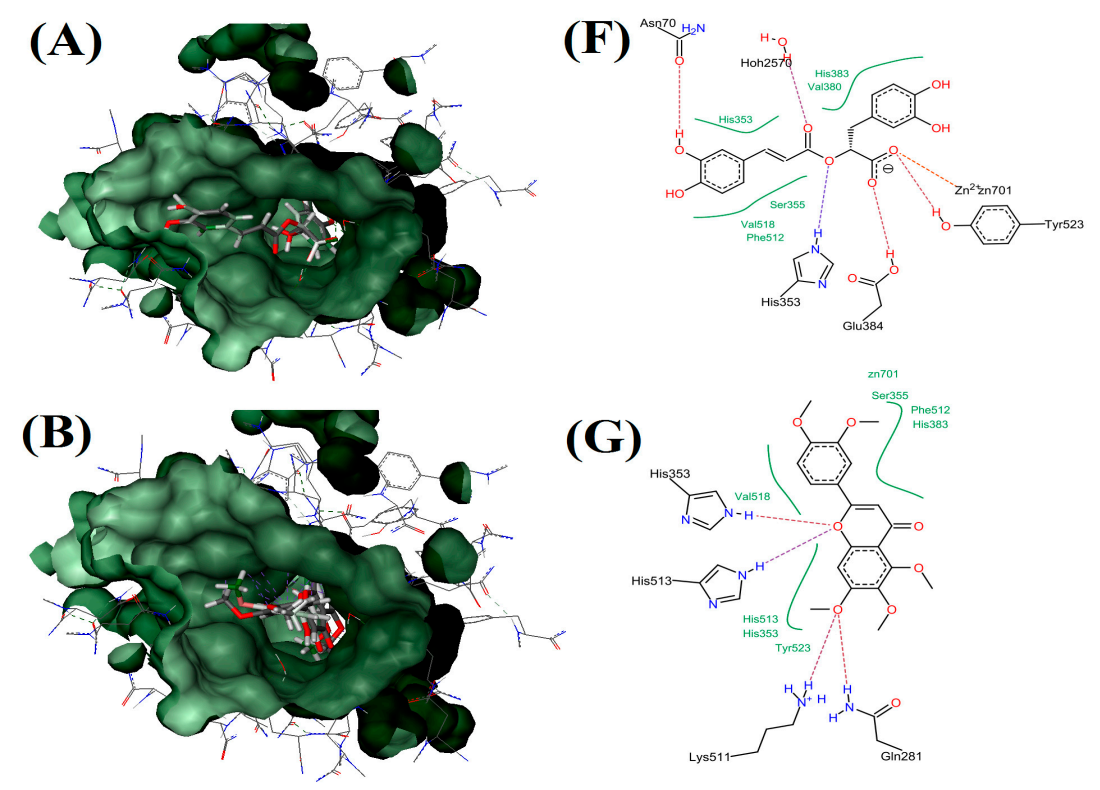

(G)
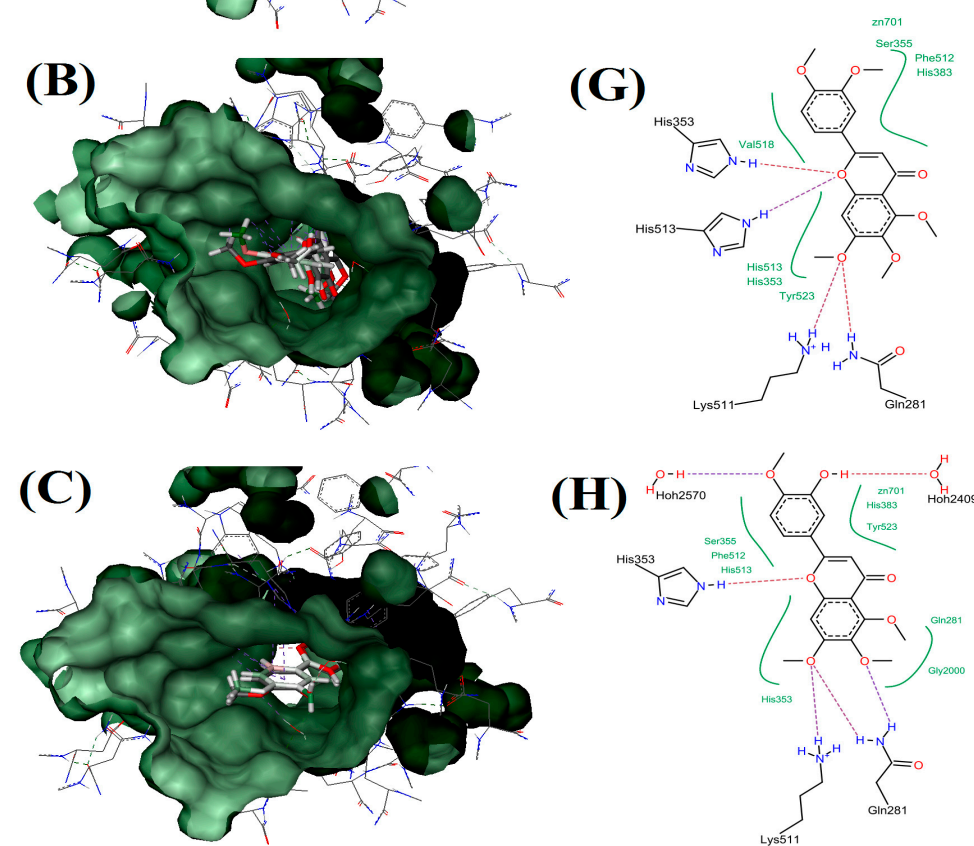

(H)
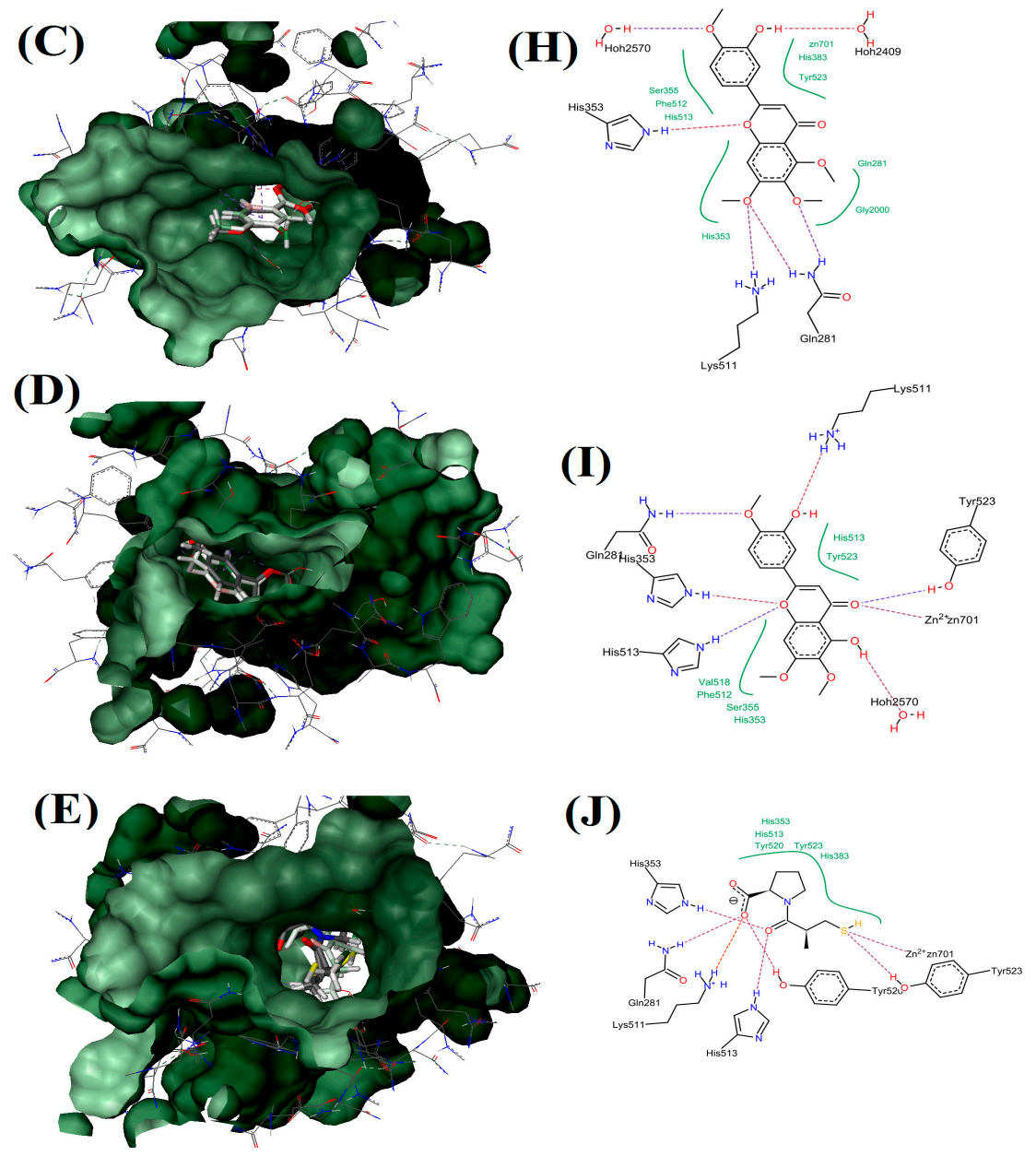

Figure 6. Visualization of ACE and OS extracts reference compounds interaction profile: Surface visualization of proteins in ACE with the ligands: RA (A); SIN (B); TMF (C); EUP (D); and Captopril (E). Active site residues interaction of protein in ACE with the ligands: RA (F); SIN (G); TMF (H); EUP (I); and Captopril (J). Hydrophobic interaction shown in green region. 


\section{Discussion}

Flavonoids compounds obtained from the plant extracts as ACE inhibitor has gained more interest during the last 10 years [6]. Many in vitro studies demonstrated the effect flavonoids as ACE inhibitors $[16,26]$. The beneficial effects of flavonoids have largely been explained by generation of chelate complexes within the active center of ACE $[19,26]$. Basically, flavonoids are polyphenolic molecules at low molecular weight with the basic structure of two phenyl rings (A and $\mathrm{C}$ rings) joined with three carbons that make a closed pyran ring structure (B ring) [41,42] (Figure 1). Furthermore, based on their structural differences, flavonoids can be divided into several subfamilies such as flavanones, flavones, flavonols, isoflavones, flavanols (essentially, flavan-3-ols) and anthocyanidins based on their degree of unsaturation and oxidation of the oxygenated heterocycle [41,43].

Previous studies have shown that flavonoid structure has played an important role in its biological function such as cytotoxicity, antioxidant and antiproliferative activities [44,45]. Moreover, several studies have shown that flavonoids are able to exhibit zinc metalloproteinases such as ACE and this activity depends on the flavonoids structure [46,47]. Although in vitro and in vivo ACE inhibition activity of some flavonoids such as quercetin and phenolics such as ferulic acid and tannic acid have been studied [20,21], the data on ACE inhibition and therefor blood pressure-reducing potency of many more flavonoids, especially those that are present in OS (a plant that has been used traditionally for treating hypertension), have not yet been studied. Therefore, in this study ACE inhibitory properties of different extracts of OS and pure phenolic acid (RA) and flavonoids (TMF, SIN and EUP) compounds that are presence in OS extract were evaluated. Moreover, the chelating activity of these compounds with Zn (II) was investigated by TMM reagent. Together with the obtained results, structure-activity relationship analysis and molecular docking were used for a better understanding of how these flavonoids compounds interact with the ACE enzyme.

The results obtained from the inhibitory effects on ACE activity of OS extracts showed that OS-E extract, which contained highest contents of flavonoids (TMF, SIN and EUP) (Table 1), exhibited highest inhibition compared to other extracts. In addition, OS-E extract, which contains a mixture of flavonoids, showed high chelating ability with $\mathrm{Zn}$ (II) and it was greater than RA, TMF, SIN or EUP alone (Figure 5). With regard to the flavonoids compounds that have been used in this study, it could be seen that presence of certain functional groups such as hydroxyl, carboxyl, and acrylic acid groups, which can act as hydrogen bond acceptors or donors, have increased the potency to inhibit ACE [6,16]. As shown in Figure 6, EUP produced more number of hydrogen bonds (seven) with the active site of ACE enzyme and therefore showed the highest ACE inhibition compared to other tested compounds, whereas RA contained more number of hydroxyl groups compared to EUP but produced less hydrogen bonds (six) compared to EUP. Restricted docking between RA and the active site of ACE failed, as a consequence of the steric hindrance. In addition, SIN was not able to produce hydrogen bond, due to the lack of suitable functional groups such as hydroxyl, carboxyl, and acrylic. This finding is in line with the in vitro ACE results. EUP showed the lowest $\mathrm{IC}_{50}$ value $(15.35 \pm 4.49 \mu \mathrm{g} / \mathrm{mL})$ and highest bounding ability with $\mathrm{Zn}$ (II) $(56.03 \% \pm 1.26 \%$ at concentration of $5 \mathrm{mg} / \mathrm{mL}$ ) compared to RA, TMF and SIN. The in vitro ACE inhibition activity and binding ability with Zn (II) of tested compounds follows the order: EUP $>$ RA $>$ TMF $>$ SIN. Similarly, protein-ligand docking studies also showed the same order: EUP $>$ RA $>$ TMF $>$ SIN.

In this study, we have demonstrated that changes in flavonoids active core affect their capacity to inhibit ACE. Moreover, we showed that ACE inhibition activity of flavonoids compounds is directly related to their ability to bind with zinc ion in the active site of ACE enzyme. In Figure 3, it can be seen that, in addition to the other four discussed compounds (RA, TMF, SIN and EUP), other compounds are present in the extracts and they might also contribute to the ACE inhibition activity. According to Siddiqui and Ismail, OS extract contained high amounts of flavonoids other than RA, TMF, SIN and EUP [48]. Therefore, the unknown compounds can be studied in future research. As such, application of OS extract is useful as inhibitors of ACE. 


\section{Materials and Methods}

\subsection{Chemicals and Reagents}

ACE enzyme (from rabbit lung), hippuryl-histidyl-leucine (HHL), hippuric acid (HA), captopril, zinc chloride, tetramethylmurexide and hexamine $/ \mathrm{HCl}$ were purchased from Sigma-Aldrich (Subang Jaya, Selangor, Malaysia). Rosmarinic acid (RA), Sinensetin (SIN), eupatorin (EUP) and $3^{\prime}$-hydroxy-5,6,7,4'-tetramethoxy flavone (TMF) standards were purchased from Indofine (Hillsborough, NJ, USA). Acetonitrile (HPLC grade), formic acid (HPLC grade) methanol (HPLC grade), orthophosphoric acid (HPLC grade), methanol (AR grade), ethanol (AR grade) and ammonium dihydrogen phosphate, monobasic dihydrogenphosphate and dibasic monohydrogen phosphate were obtained from Merck (Petaling Jaya, Selangor, Malaysia). Deionized water for HPLC was prepared using ultra-pure water purifier system (Elgastat, Bucks, UK).

\subsection{Plant Material and Extraction}

In the current study, the leaves of Orthosiphon stamineus (OS) were purchased from Herbagus Sdn. Bhd. Penang-Malaysia and identified by Mr. Shunmugam from the school of Biological Sciences, University Sains Malaysia. A voucher specimen (no. 11009) was deposited at the herbarium of School of Biological Sciences, University Sains Malaysia. The leaves were oven-dried at $40{ }^{\circ} \mathrm{C}$ and then pulverized into fine powder using a milling machine (Retsch $\mathrm{GmbH}$, Haan, Germany). In preparing extracts, $100 \mathrm{~g}$ powder was extracted with $500 \mathrm{~mL}$ of water (OS-W), ethanol (OS-E), methanol (OS-M), 50\% ethanol (OS-EW) and 50\% methanol (OS-MW) using maceration method for $48 \mathrm{~h}$ at $50{ }^{\circ} \mathrm{C}$. After cooling, the extracts were filtered using Whatman filter paper No. 1 (Whatman, Kent, England), concentrated at $50{ }^{\circ} \mathrm{C}$ under vacuum using a rotary evaporator (RE121 Buchi, Flawil, Switzerland), and dried using a freeze-drying system (Labconco, Kansas City, MO, USA).

\subsection{Identification and Quantification of RA, TMF, SIN and EUP in OS Extracts}

\subsubsection{HPLC Mass Spectrometry}

The High Performance Liquid Chromatography Mass Spectrometry (HPLC/MS) was used for identification of RA, TMF, SIN and EUP in different extracts of OS. An Accela Thermo Finnigan LCQ DUO (Mundelein, IL, USA) system equipped with an ESI source was used in this study. The standard compounds of RA, TMF, SIN and EUP were prepared separately in MS grade methanol and $20 \mu \mathrm{L}$ of each compound was injected through HPLC into ESI probe. The operating conditions were as follows: Colum; Poroshell 120 EC-C18, $2.7 \mu \mathrm{m}$ (Agilent, Santa Clara, CA, USA), column dimension $2.1 \times 100 \mathrm{~mm}$, part number: USCGC 01268; mobile phase, methanol and $0.1 \%$ formic acid (90:10) at a flow rate $0.3 \mathrm{~mL} / \mathrm{min}$; the capillary temperature, $220{ }^{\circ} \mathrm{C}$; capillary voltage, $4 \mathrm{kV}$; drying gas $\left(\mathrm{N}_{2}\right)$ flow, $12 \mathrm{~L} / \mathrm{min}$; nebulizer $\left(\mathrm{N}_{2}\right)$ pressure, 35 pis. Full scan data acquisition was performed from $m / z 105$ to 500 units in MS scan mode.

\subsubsection{HPLC}

The High Performance Liquid Chromatography (HPLC) analysis was used for quantification of RA, TMF, SIN and EUP in different extracts of OS. HPLC analysis was performed using an Agilent Technologies (Series 1200 infinity, Frankfurt, Germany) system. Separations were accomplished on Nucleosil C18 column $(250 \times 4.6 \mathrm{~mm}$ internal diameter $\times 5 \mu \mathrm{m}$ particles size) (Macherey Nagel, Düren, Germany) and column temperature was marinated at $25{ }^{\circ} \mathrm{C}$ and the injection sample $(20 \mu \mathrm{L})$ was eluted at isocratic system comprising of methanol: tetrahydrofuran: water $\left(0.1 \% \mathrm{H}_{3} \mathrm{PO}_{4}\right)$ mixture in the volume ratio 55: 5: 40. Flow rate was $0.7 \mathrm{~mL} / \mathrm{min}$ and detector was set at $330 \mathrm{~nm}$ [48]. 


\subsection{In Vitro ACE Inhibition Activity}

Assay for measuring ACE inhibitory activity was described by Chushman and Cheung (1971) [32]. This method relies on determining hippuric acid (HA) formation from ACE-specific substrate hippuryl-histidyl-leucine (HHL) by the action of ACE enzyme, resulting in the removal of C-terminal dipeptide histidylleucine.

\subsubsection{HPLC Method for Measurement of ACE Inhibition Activity}

\section{Chromatographic Condition}

The high performance liquid chromatography (HPLC) was performed using an Agilent Technologies (Series 1200 infinity, Frankfurt, Germany) system. Separations were accomplished on a Zorbax Eclipse plus phenyl-hexyl ( $4.6 \mathrm{~mm} \times 250 \mathrm{~mm}, 5 \mu \mathrm{m}$, Agilent) and the column temperature was maintained at $30{ }^{\circ} \mathrm{C}$. Substrates of HA and HHL were detected at $228 \mathrm{~nm}$. The flow rate was set at $0.6 \mathrm{~mL} / \mathrm{min}$ and injection volume was $10 \mu \mathrm{L}$. The mobile phase consisted of $20 \%$ acetonitrile and $80 \%$ of $0.1 \%$ ammonium dihydrogen phosphate buffer was used in this analysis with $10 \mathrm{~min}$ separation time.

\section{HA Calibration Curve}

To construct a calibration curve, a series of HA solutions $(0.488-31.25 \mu \mathrm{g} / \mathrm{mL})$ were prepared in water. The calibration was constructed by plotting the relative peak area of the HA versus concentration of HA in triplicate at 7 different concentrations.

\section{ACE Calibration Curve}

For substrate HHL hydrolysis catalyzed by purified rabbit ACE enzyme, the total reaction volume was $200 \mu \mathrm{L}$. Phosphate buffer ( $\mathrm{pH}$ 8.3) was used to dilute the substrate HHL and rabbit lung ACE enzyme. To $100 \mu \mathrm{L}$ of $10 \mathrm{mM}$ HHL substrate, $100 \mu \mathrm{L}$ of ACE enzyme solution with various concentrations was added $(0.05-0.00157 \mathrm{U} / \mathrm{mL})$. The reaction mixtures were incubated for $2 \mathrm{~h}$ at $37^{\circ} \mathrm{C}$. The reaction was terminated by heating the samples at $100{ }^{\circ} \mathrm{C}$ in water bath, and then $800 \mu \mathrm{L}$ of water was added to all samples, and they were analyzed by stated HPLC method.

\section{Validation of HPLC Method}

The developed HPLC method was validated in terms of accuracy, precision, linearity range, limit of detection (LOD), and limit of quantification (LOQ) according to the ICH guideline [49]. Accuracy of the HPLC method was evaluated through recovery studies by adding known amounts of HA solution $(25,12.5,6.25,3.125$ and $1.5625 \mu \mathrm{g} / \mathrm{mL})$ into the mixture of HA and HHL at $25 \mu \mathrm{g} / \mathrm{mL}$. The spiked HA solutions were injected three times and the recovery was calculated with the value of detected versus added amounts. The intra-day and inter-day precisions were determined for evaluation of method precision. The intra-day precision was evaluated by injecting seven different concentrations of the standards five times for one day to HPLC system, while inter-day precision was obtained by injecting seven different concentrations of the standards one time for five consecutive days. The resulting peak area was used to calculate standard deviation (SD) and the relative standard deviation (\%RSD). The linearity of methods was constructed using calibration curve of HA and ACE over different concentrations in triplicate. LOD and LOQ were measured based on the standard deviation of the response and the slope was assessed according to the following equations:

$$
\begin{aligned}
& \mathrm{LOD}=3.3 \sigma / \mathrm{S} \\
& \mathrm{LOQ}=10 \sigma / \mathrm{S}
\end{aligned}
$$

where $\sigma$ is the standard deviation of the response and $S$ is the slope of the calibration curve. 


\subsection{In Vitro ACE Inhibition Activity}

Sample Preparation with the Purified Rabbit Lung ACE

Captopril was used as positive control in this assay at different concentrations $(0.0020-0.0625 \mu \mathrm{M})$. RA, TMF, SIN and EUP as reference compounds were also used $(1.5625-50 \mu \mathrm{g} / \mathrm{mL})$. HHL as substrate was prepared freshly in $10 \mathrm{mM}$ phosphate buffer $\mathrm{pH} 8.3$ and then sonicated for $30 \mathrm{~min}$. Stock solutions of extracts were prepared by dissolving $5 \mathrm{mg}$ of each extract in the same solvent used for extraction. Working sample solution was prepared by diluting the stock solution with $50 \%$ ethanol $(1.5625-50 \mu \mathrm{g} / \mathrm{mL})$. Angiotensin converting enzyme (ACE) was prepared at $0.05 \mathrm{U} / \mathrm{mL}$ in phosphate buffer $\mathrm{pH} 8.3$ containing $0.1 \%$ bovine serum albumin (BSA). Then, $50 \mu \mathrm{L}$ of purified ACE enzyme and $20 \mu \mathrm{L}$ extracts, reference compounds or captopril at different concentrations were added to $130 \mu \mathrm{L}$ of HHL substrate. Control reaction mixture was contained $20 \mu \mathrm{L}$ of $50 \%$ ethanol instead of extracts. All samples were incubated for $2 \mathrm{~h}$ at $37^{\circ} \mathrm{C}$. The reaction was stopped by heating the samples at $100{ }^{\circ} \mathrm{C}$. All samples were analyzed by HPLC after adding $800 \mu \mathrm{L}$ of water. ACE inhibition rate was calculated by the following equation:

ACE inhibition activity of test substances $(\%)=[$ (HA concentration levels without test substances) - (HA concentration levels with test substances)/(HA concentration levels without test substances)] $\times 100$

All analyses were performed thrice and their results are presented as the mean \pm standard deviation (SD). If the test substance displayed inhibition activity toward ACE, these values would be increased significantly (up to 100\%). On the other hand, if the substance did not display inhibition activity, these values would only be altered slightly by the test substances.

\subsection{Chelation of Zinc Ion (II) by OS-E, RA, TMF, SIN, EUP and Captopril}

Capacity of zinc Ion (II) chelation by captopril, RA, TMF, SIN, EUP and OS-E was determined using a method described by Karamać [50]. Briefly, $0.01 \mathrm{M}$ hexamine $/ \mathrm{HCl}$ buffer was prepared at pH 5.0 with addition of $0.01 \mathrm{M} \mathrm{KCl}$. Stock solution of captopril. RA, TMF, SIN, EUP, and OS-E were prepared in hexamine $/ \mathrm{HCl}$ at concentration of $5 \mathrm{mg} / \mathrm{mL}$. A series of working sample solutions were prepared by diluting the stock solutions with hexamine/ $\mathrm{HCl}$ buffer $(0-5 \mathrm{mg} / \mathrm{mL}) . \mathrm{ZnCl}_{2}$ was prepared in the same buffer at concentration of $0.8 \mathrm{mM}$. Then, $1 \mathrm{~mL}$ of sample solutions was mixed with $1 \mathrm{~mL}$ $\mathrm{ZnCl}_{2}$ solution and $0.1 \mathrm{~mL}$ tetramethylmurexide at concentration of $1 \mathrm{mM}$. Absorbance was recorded at $462 \mathrm{~nm}$ and $530 \mathrm{~nm}$ and then the ratio of A462/A530 was calculated. Distilled deionized water was used instead of tetramethylmurexide reagent in control samples. A standard curve of absorbance ratio versus metal ions concentrations ( 0 to $3.2 \mathrm{mM}$ ) was prepared and the percentage of bound metal ions was calculated.

Percentage of bond with $\mathrm{Zn}^{2+}=1-\left(\right.$ Concentration of free $\mathrm{Zn}^{2+} /$ Concentration of total $\left.\mathrm{Zn}^{2+}\right) \times 100$

\subsection{Molecular Docking Study}

3D Ligand structure of RA, TMF, SIN, EUP, and captopril (positive control) were drawn in ChemBio Draw and 3D Protein structure of Angiotensin Converting Enzyme (ACE; PDB:1O86) were downloaded from RCSB protein data bank. RA, TMF, SIN, EUP and captopril structures were further studied for their possible binding with active site of ACE enzyme, which is $\mathrm{Zn}^{2+}$ or protein-ligand, by docking studies using LeadIT-FlexX: BioSolveIT's LeadIT program.

LeadIT-FlexX: BioSolveIT's LeadIT program was used to dock the compounds as flexible function of FlexX algorithm [51]. This program detects the binding site according to reference ligand by superimposition of the experimented ligand. In addition, active site was defined by selecting the residue 
of the protein with $10 \AA$ on the center of the ligand. Top 10 poses were selected to analyze the free binding energy $(\Delta G)$ of the protein-ligand complex and ligand efficiency using Hyde assessment [52].

\section{Conclusions}

In this study, we have successfully developed and validated a new HPLC-UV method for measurement of ACE activity in OS plant extracts and its reference compounds (RA, TMF, SIN and EUP). Moreover, we have demonstrated that changes in the flavonoid active core affect its capacity to inhibit the ACE, and production of chelate with Zn (II) ion. In addition, docking study on the reference compounds of OS also confirmed that the RA, TMF, SIN and EUP present in OS extracts are able to inhibit ACE via interaction with $\mathrm{Zn}$ (II) ion and this interaction is stabilized by other interactions with amino acids in the active site. Therefore, the information provided in this study can be useful for designing new ACE inhibitors based on flavonoids compounds.

Acknowledgments: The authors would like to acknowledge Universiti Sains Malaysia for financial support given under the USM Fellowship Scheme. This project was funded by the Malaysian Ministry of Agriculture and Agro-Based Industry, NKEA Research Grant Scheme (NRGS), Ref. No.: 304/PFRMASI/650582/K123.

Author Contributions: A.F.A.A., A.M.S.A.M., M.N.M. and Z.I. conceived and designed the experiments; A.S. and M.S.S.K., M.R.H. and A.F.A.A. performed the experiments; A.S., A.F.A.A., M.N.M. and M.S.S.K. analyzed the data; Z.I. and A.M.S.A. contributed reagents/materials/analysis tools; A.S. wrote the paper.

Conflicts of Interest: The authors declare no conflict of interest.

\section{References}

1. Kearney, P.M.; Whelton, M.; Reynolds, K.; Muntner, P.; Whelton, P.K.; He, J. Global burden of hypertension: Analysis of worldwide data. Lancet 2005, 365, 217-223. [CrossRef]

2. Hartmann, R.; Meisel, H. Food-derived peptides with biological activity: From research to food applications. Curr. Opin. Biotechnol. 2007, 18, 163-169. [CrossRef] [PubMed]

3. Mittal, B.V.; Singh, A.K. Hypertension in the developing world: Challenges and opportunities. Am. J. Kidney Dis. 2010, 55, 590-598. [CrossRef] [PubMed]

4. Maruthur, N.M.; Wang, N.-Y.; Appel, L.J. Lifestyle interventions reduce coronary heart disease risk results from the premier trial. Circulation 2009, 119, 2026-2031. [CrossRef] [PubMed]

5. Coates, D. The angiotensin converting enzyme (ACE). Int. J. Biochem. Cell Biol. 2003, 35, 769-773. [CrossRef]

6. Al Shukor, N.; Van Camp, J.; Gonzales, G.B.; Staljanssens, D.; Struijs, K.; Zotti, M.J.; Raes, K.; Smagghe, G. Angiotensin-converting enzyme inhibitory effects by plant phenolic compounds: A study of structure activity relationships. J. Agric. Food Chem. 2013, 61, 11832-11839. [CrossRef] [PubMed]

7. Pfeffer, M.A.; Frohlich, E.D. Improvements in clinical outcomes with the use of angiotensin-converting enzyme inhibitors: Cross-fertilization between clinical and basic investigation. Am. J. Physiol. Heart Circ. Physiol. 2006, 291, H2021-H2025. [CrossRef] [PubMed]

8. Israili, Z.H.; Hall, W.D. Cough and angioneurotic edema associated with angiotensin-converting enzyme inhibitor therapy: A review of the literature and pathophysiology. Ann. Intern. Med. 1992, 117, $234-242$. [CrossRef] [PubMed]

9. Opie, L. Ace inhibitors in pregnancy: How to avoid the sting in the tail. S. Afr. Med. J. 1996, 86, 326-327. [PubMed]

10. Nyman, U.; Joshi, P.; Madsen, L.; Pedersen, T.; Pinstrup, M.; Rajasekharan, S.; George, V.; Pushpangadan, P. Ethnomedical information and in vitro screening for angiotensin-converting enzyme inhibition of plants utilized as traditional medicines in gujarat, rajasthan and kerala (india). J. Ethnopharmacol. 1998, 60, 247-263. [CrossRef]

11. Park, P.-J.; Je, J.-Y.; Kim, S.-K. Angiotensin i converting enzyme (ace) inhibitory activity of hetero-chitooligosaccharides prepared from partially different deacetylated chitosans. J. Agric. Food Chem. 2003, 51, 4930-4934. [CrossRef] [PubMed]

12. Heran, B.S.; Wong, M.M.; Heran, I.K.; Wright, J.M. Blood pressure lowering efficacy of angiotensin converting enzyme (ace) inhibitors for primary hypertension. Cochrane Libr. 2008. [CrossRef] 
13. Cinq-Mars, C.D.; Li-Chan, E.C. Optimizing angiotensin I-converting enzyme inhibitory activity of pacific hake (merluccius productus) fillet hydrolysate using response surface methodology and ultrafiltration. J. Agric. Food Chem. 2007, 55, 9380-9388. [CrossRef] [PubMed]

14. Vercruysse, L.; Van Camp, J.; Smagghe, G. Ace inhibitory peptides derived from enzymatic hydrolysates of animal muscle protein: A review. J. Agric. Food Chem. 2005, 53, 8106-8115. [CrossRef] [PubMed]

15. Somova, L.; Nadar, A.; Rammanan, P.; Shode, F. Cardiovascular, antihyperlipidemic and antioxidant effects of oleanolic and ursolic acids in experimental hypertension. Phytomedicine 2003, 10, 115-121. [CrossRef] [PubMed]

16. Guerrero, L.; Castillo, J.; Quiñones, M.; Garcia-Vallvé, S.; Arola, L.; Pujadas, G.; Muguerza, B. Inhibition of angiotensin-converting enzyme activity by flavonoids: Structure-activity relationship studies. PLoS ONE 2012, 7, e49493. [CrossRef] [PubMed]

17. Dong, J.; Xu, X.; Liang, Y.; Head, R.; Bennett, L. Inhibition of angiotensin converting enzyme (ace) activity by polyphenols from tea (Camellia sinensis) and links to processing method. Food Funct. 2011, 2, 310-319. [CrossRef] [PubMed]

18. Ojeda, D.; Jiménez-Ferrer, E.; Zamilpa, A.; Herrera-Arellano, A.; Tortoriello, J.; Alvarez, L. Inhibition of angiotensin convertin enzyme (ACE) activity by the anthocyanins delphinidin-and cyanidin-3-O-sambubiosides from Hibiscus sabdariffa. J. Ethnopharmacol. 2010, 127, 7-10. [CrossRef] [PubMed]

19. Loizzo, M.R.; Said, A.; Tundis, R.; Rashed, K.; Statti, G.A.; Hufner, A.; Menichini, F. Inhibition of angiotensin converting enzyme (ACE) by flavonoids isolated from Ailanthus excelsa (Roxb) (Simaroubaceae). Phytother. Res. 2007, 21, 32-36. [CrossRef] [PubMed]

20. Häckl, L.; Cuttle, G.; Sanches Dovichi, S.; Lima-Landman, M.; Nicolau, M. Inhibition of angiotensin-converting enzyme by quercetin alters the vascular response to bradykinin and angiotensin I. Pharmacology 2002, 65, 182-186. [CrossRef] [PubMed]

21. Alam, M.A.; Sernia, C.; Brown, L. Ferulic acid improves cardiovascular and kidney structure and function in hypertensive rats. J. Cardiovasc. Pharmacol. 2013, 61, 240-249. [CrossRef] [PubMed]

22. Actis-Goretta, L.; Ottaviani, J.I.; Keen, C.L.; Fraga, C.G. Inhibition of angiotensin converting enzyme (ACE) activity by flavan-3-ols and procyanidins. FEBS Lett. 2003, 555, 597-600. [CrossRef]

23. Kwon, E.-K.; Lee, D.-Y.; Lee, H.; Kim, D.-O.; Baek, N.-I.; Kim, Y.-E.; Kim, H.-Y. Flavonoids from the buds of Rosa damascena inhibit the activity of 3-hydroxy-3-methylglutaryl-coenzyme a reductase and angiotensin I-converting enzyme. J. Agric. Food Chem. 2009, 58, 882-886. [CrossRef] [PubMed]

24. Bormann, H.; Melzig, M. Inhibition of metallopeptidases by flavonoids and related compounds. Die Pharm. 2000, 55, 129-132.

25. Yesudas, R.; Gumaste, U.; Snyder, R.; Thekkumkara, T. Tannic acid down-regulates the angiotensin type 1 receptor through a mapk-dependent mechanism. Mol. Endocrinol. 2012, 26, 458-470. [CrossRef] [PubMed]

26. Balasuriya, B.N.; Rupasinghe, H.V. Plant flavonoids as angiotensin converting enzyme inhibitors in regulation of hypertension. Funct. Foods Health Dis. 2011, 1, 172-188.

27. Quiñones, M.; Sánchez, D.; Muguerza, B.; Miguel, M.; Aleixandre, A. Mechanisms for antihypertensive effect of cocoanox, a polyphenol-rich cocoa powder, in spontaneously hypertensive rats. Food Res. Int. 2011, 44, 1203-1208. [CrossRef]

28. Junior, A.G.; Gasparotto, F.M.; Lourenço, E.L.B.; Crestani, S.; Stefanello, M.E.A.; Salvador, M.J.; da Silva-Santos, J.E.; Marques, M.C.A.; Kassuya, C.A.L. Antihypertensive effects of isoquercitrin and extracts from Tropaeolum majus L.: Evidence for the inhibition of angiotensin converting enzyme. J. Ethnopharmacol. 2011, 134, 363-372. [CrossRef] [PubMed]

29. Lahogue, V.; Réhel, K.; Taupin, L.; Haras, D.; Allaume, P. A HPLC-UV method for the determination of angiotensin I-converting enzyme (ACE) inhibitory activity. Food Chem. 2010, 118, 870-875. [CrossRef]

30. Alves, M.; Araujo, M.d.C.; Juliano, M.A.; Oliveira, E.M.d.; Krieger, J.E.; Casarini, D.E.; Juliano, L.; Carmona, A.K. A continuous fluorescent assay for the determination of plasma and tissue angiotensin I-converting enzyme activity. Braz. J. Med. Biol. Res. 2005, 38, 861-868. [CrossRef] [PubMed]

31. Sentandreu, M.Á.; Toldrá, F. A rapid, simple and sensitive fluorescence method for the assay of angiotensin-I converting enzyme. Food Chem. 2006, 97, 546-554. [CrossRef]

32. Cushman, D.; Cheung, H. Spectrophotometric assay and properties of the angiotensin-converting enzyme of rabbit lung. Biochem. Pharmacol. 1971, 20, 1637-1648. [CrossRef] 
33. Inoue, K.; Kitade, M.; Hino, T.; Oka, H. Screening assay of angiotensin-converting enzyme inhibitory activity from complex natural colourants and foods using high-throughput LC-MS/MS. Food Chem. 2011, 126, 1909-1915. [CrossRef] [PubMed]

34. Miguel, M.; Manso, M.A.; Martín-Álvarez, P.J.; Aleixandre, A.; López-Fandiño, R. Angiotensin-converting enzyme activity in plasma and tissues of spontaneously hypertensive rats after the short-and long-term intake of hydrolysed egg white. Mol. Nutr. Food Res. 2007, 51, 555-563. [CrossRef] [PubMed]

35. Mohamed, E.A.H.; Mohamed, A.J.; Asmawi, M.Z.; Sadikun, A.; Ebrika, O.S.; Yam, M.F. Antihyperglycemic effect of orthosiphon stamineus benth leaves extract and its bioassay-guided fractions. Molecules 2011, 16, 3787-3801. [CrossRef] [PubMed]

36. Matsubara, T.; Bohgaki, T.; Watarai, M.; Suzuki, H.; Ohashi, K.; Shibuya, H. Antihypertensive actions of methylripariochromene a from Orthosiphon aristatus, an Indonesian traditional medicinal plant. Biol. Pharm. Bull. 1999, 22, 1083-1088. [CrossRef] [PubMed]

37. Arafat, O.; Tham, S.; Sadikun, A.; Zhari, I.; Haughton, P.; Asmawi, M. Studies on diuretic and hypouricemic effects of Orthosiphon stamineus methanol extracts in rats. J. Ethnopharmacol. 2008, 118, 354-360. [CrossRef] [PubMed]

38. Dolečková, I.; Rárová, L.; Grúz, J.; Vondrusová, M.; Strnad, M.; Kryštof, V. Antiproliferative and antiangiogenic effects of flavone eupatorin, an active constituent of chloroform extract of Orthosiphon stamineus leaves. Fitoterapia 2012, 83, 1000-1007. [CrossRef] [PubMed]

39. Akowuah, G.; Zhari, I.; Norhayati, I.; Sadikun, A.; Khamsah, S. Sinensetin, eupatorin, 3'-hydroxy-5,6,7,4'-tetramethoxyflavone and rosmarinic acid contents and antioxidative effect of Orthosiphon stamineus from Malaysia. Food Chem. 2004, 87, 559-566. [CrossRef]

40. Akowuah, G.; Ismail, Z.; Norhayati, I.; Sadikun, A. The effects of different extraction solvents of varying polarities on polyphenols of orthosiphon stamineus and evaluation of the free radical-scavenging activity. Food Chem. 2005, 93, 311-317. [CrossRef]

41. Corradini, E.; Foglia, P.; Giansanti, P.; Gubbiotti, R.; Samperi, R.; Laganà, A. Flavonoids: Chemical properties and analytical methodologies of identification and quantitation in foods and plants. Natl. Prod. Res. 2011, 25, 469-495. [CrossRef] [PubMed]

42. Hughes, R.J.; Croley, T.R.; Metcalfe, C.D.; March, R.E. A tandem mass spectrometric study of selected characteristic flavonoids. Int. J. Mass Spectrom. 2001, 210, 371-385. [CrossRef]

43. Fraga, C.G.; Galleano, M.; Verstraeten, S.V.; Oteiza, P.I. Basic biochemical mechanisms behind the health benefits of polyphenols. Mol. Asp. Med. 2010, 31, 435-445. [CrossRef] [PubMed]

44. Navarro-Nunez, L.; Castillo, J.; Lozano, M.L.; Martinez, C.; Benavente-García, O.; Vicente, V.; Rivera, J. Thromboxane a2 receptor antagonism by flavonoids: Structure-activity relationships. J. Agric. Food Chem. 2009, 57, 1589-1594. [CrossRef] [PubMed]

45. Benavente-Garcia, O.; Castillo, J.; Lorente, J.; Ortuno, A.; Del Rio, J. Antioxidant activity of phenolics extracted from Olea europaea L. Leaves. Food Chem. 2000, 68, 457-462. [CrossRef]

46. Parellada, J.; Suárez, G.; Guinea, M. Inhibition of zinc metallopeptidases by flavonoids and related phenolic compounds: Structure-activity relationships. J. Enzym. Inhib. 1998, 13, 347-359. [CrossRef] [PubMed]

47. Ende, C.; Gebhardt, R. Inhibition of matrix metalloproteinase-2 and-9 activities by selected flavonoids. Planta Med. 2004, 70, 1006-1008. [CrossRef] [PubMed]

48. Siddiqui, M.J.A.; Ismail, Z. Simultaneous analysis of bioactive markers from Orthosiphon stamineus benth leaves extracts by reverse phase high performance liquid chromatography. Trop. J. Pharm. Res. 2011, 10, 97-103. [CrossRef]

49. International Conference on Harmonization. Validation of Analytical Procedures: Methodology (Q2B); FDA: Rockville, MD, USA, 1996.

50. Karamać, M. Chelation of Cu (II), Zn (II), and Fe (II) by tannin constituents of selected edible nuts. Int. J. Mol. Sci. 2009, 10, 5485-5497. [CrossRef] [PubMed]

51. Böhm, H.-J. Prediction of binding constants of protein ligands: A fast method for the prioritization of hits obtained from de novo design or 3D database search programs. J. Comput. Aided Mol. Des. 1998, 12, 309-309. [CrossRef] [PubMed] 
52. Rarey, M.; Kramer, B.; Lengauer, T.; Klebe, G. A fast flexible docking method using an incremental construction algorithm. J. Mol. Biol. 1996, 261, 470-489. [CrossRef] [PubMed]

Sample Availability: Samples of the compounds RA, TMF, SIN and EUP are available from the authors. 